\title{
Meat Quality Traits of Longissimus Muscle of Hanwoo Steers as a Function of Interaction between Slaughter Endpoint and Chiller Ageing
}

\author{
Dashmaa Dashdorj, Maria Cynthia R. Oliveros ${ }^{1}$, and Inho Hwang* \\ Department of Animal Science and Institute of Rare Earth for Biological Application, Chonbuk National University, \\ Jeonju 561-756, Korea \\ ${ }^{1}$ Animal and Dairy Science Cluster, College of Agriculture, University of the Philippines, Los Banos, Philippine 4031
}

\begin{abstract}
Carcass characteristics and meat quality traits as a function of endpoint months of slaughter age (26 vs 32 mon) and chiller ageing ( 1 vs $10 \mathrm{~d}$ ) were evaluated for $m$. longissmus of 26 Hanwoo steers fed with commercial diets including whole crop barley silage. Totally twenty six Hanwoo steers for 6 mon of age that were fed until 26 mon of age constituted the short termfed group and fed until 32 mon of age constituted long-term fed group. Carcasses were chilled for $24 \mathrm{~h}$ and were graded. Strip loin samples were divided into two age groups $(1 \mathrm{~d}$ and $10 \mathrm{~d}$ ). Long-term feeding increased carcass weight, rib-eye area, yield grade, marbling score, firmness and quality grade of the meat. The feeding for 32 mon produced tender, juicy meat $(p<0.01)$ with lower cooking loss and higher rating score $(p<0.05)$ than short term feeding, while other quality traits were not influenced by the length of feeding. Intramuscular fat content and oxidative stability (TBARS value) were significantly $(p<0.05)$ higher in beef from long-term feeding however the length of feeding did not alter the fatty acid composition. Chiller aging reduced instrumental tenderness (WBSF value), improved color, sensory tenderness, acceptability and rating of beef. The results of the present study mirrors that Hanwoo steers until 32 mon of age overall improved carcass traits and palatability compared to that for $26 \mathrm{mon}$. However, from the viewpoints of economical and environmental aspects, cost of the additional feeding for 6 mon for value-adding of eating quality was relatively high and the effects in turn were limited.
\end{abstract}

Key words: Hanwoo beef, barley-based diet, meat quality, length of feeding

\section{Introduction}

Historic slaughter weight of Hanwoo has been approximately $400 \mathrm{~kg}$ or lighter but in the past decade the endpoint weight has been increased up to $700 \mathrm{~kg}$ or heaver (Park et al., 2002), as that improves palatability associated with fattening and maturation. Feeding grain and increasing time on feed improve the palatability and acceptability of meat for the US consumer, primarily by increasing the amount of marbling (Hausman et al., 2009). Likewise, several researches have demonstrated that carcass characteristics are generally influenced by time on a finishing diet. Camfield et al. (1997) observed that feeding crossbred steers with a concentrate finishing diet for $90 \mathrm{~d}$ after $150 \mathrm{~d}$ of grazing Bermuda grass has a positive influence on the characteristics of carcasses. For

\footnotetext{
*Corresponding author: Inho Hwang, Department of Animal Science and Institute of Rare Earth for Biological Application, Chonbuk National University, Jeonju 561-756, Korea. Tel: 82-63270-2605, Fax: 82-63-270-2605; E-mail: inho.hwang@jbnu.ac.kr
}

16 mon old Angus $\times$ Hereford steers fed grass during the growing period, ad libitum feeding of high concentrate finishing diet for $112 \mathrm{~d}$ is needed to reach the U.S. choice quality grade (Duckett et al., 1993). It was demonstrated that increased time on feed improved carcass characteristics; however, feeding beyond $112 \mathrm{~d}$ did not increase intramuscular fat deposition or enhance palatability of rib steaks. May et al. (1992) noted that most carcass grade traits increased linearly with days on feed, whereas most sensory panel variables and marbling increased curvilinearly. In contrast, Okumura et al. (2007) reported that the additional fattening period of 6 mon from 24 to 30 mon of age in Japanese Black steers results in an increase in intramuscular fat which improves the quality grade.

The length of time cattle are fed a high concentrate diet and marbling affect cooked meat flavor and palatability (Miller et al., 1996). Longer feeding with high concentrate diets resulted in higher beef flavor intensity (Bowling et al., 1978; Tatum et al., 1980), tenderness and overall acceptability (Epley et al., 1968). However, Epley et al. (1968) noted that there was no further improvement 
in sensory quality traits after $139 \mathrm{~d}$ on feed. The greatest improvement in tenderness was observed after $90 \mathrm{~d}$ (Camfield et al., 1997), $112 \mathrm{~d}$ (May et al., 1992), $56 \mathrm{~d}$ (Miller et al., 1987) and $180 \mathrm{~d}$ (Zinn et al., 1970) on high concentrate finishing diet. The decreased tenderness observed beyond the mentioned feeding periods was partly attributed to the advanced age of the animals at slaughter. On the other hand, Burson et al. (1980) noted that time on feed and diet energy density had no influence on taste panel sensory scores of beef longissimus muscle from Angus yearling steers. Dinius and Cross (1978) reported that ad libitum feeding had little influence on the cooking properties and palatability of beef from Hereford steers.

Beef quality depends not only on the degree of marbling but also on fatty acid composition (Oka et al., 2002). Diet, species, fatness, age/weight, site of deposition, gender, breed and temperature affect fatty acid composition of adipose and muscle tissues (Sami et al., 2004). Several studies have demonstrated that the time on feed had only a small effect on the fatty acid composition of beef as compared with the type of diet (Mandell et al., 1998; Rule et al., 1997; Sami et al., 2004). Marmer et al. (1984) reported that forages are high in the n-3 series precursor fatty acid 18:3 (á-linolenic) and grains are higher in the n6 series precursor fatty acid 18:2 (linoleic). Sami et al., (2004) noted that concentrate feeding in comparison with pasture grazing significantly decreased the n-3 fatty acids in beef. Similarly, Ponnampalam et al., (2006) reported that grain feeding decreased long-chain n-3 fatty acid and conjugated linolenic acid while total trans 18:1 and saturated fatty acids (SFA) were increased in Australian beef. On the other hand, Stelzeni and Johnson (2008) observed that SFA and monounsaturated fatty acids (MUFA) did not change as time on concentrate feed increased. In contrast, MUFA increased as feeding period increased from 0 to $90 \mathrm{~d}$ (Camfield et al., 1997) and 0 to $196 \mathrm{~d}$ (Duckett et al., 1993) in high concentrate diet due to increased concentration of oleic acid in the meat tissue. Sami et al. (2004) reported that oleic acid was positively associated with taste panel tenderness and flavor ratings and was negatively associated with WBSF values of longissimus muscle from Simmental bulls. Oka et al. (2000) showed that MUFA was positively correlated while SFA and PUFA were negatively correlated with meat quality score and marbling score. Wood et al. (2003) disclosed that fatty acids influence fat tissue firmness, shelf life (oxidative stability) and flavor. However Dinius and Cross (1978) did not observe any effect of the change in fatty acid composition on meat palatability.
The decrease in shear force values during postmortem ageing results from the proteolysis of myofibrillar proteins which is partly mediated by calpains (Koohmarie, 1996). Brewer et al. (2007) reported that increasing time from 7 to $21 \mathrm{~d}$ of postmortem ageing produced steaks with lower WBSF values. In addition, ageing had no effect on juiciness, flavor, $\mathrm{pH}$, lipid content and water content of steaks (Brewer and Novakofski, 2008). Similar findings were obtained by Laster et al. (2008) who found that ageing period, ageing treatment and quality grade had no significant effect on consumer sensory attributes of top sirloin steaks. On the contrary, French et al. (2001) observed improvements in the sensory profile of beef with increased postmortem ageing. Lee et al. (2008) have demonstrated that ageing periods affect color development with meat aged for $14 \mathrm{~d}$ or less, having a more vivid, redder and more yellow color as compared to beef aged for 28 or $35 \mathrm{~d}$.

Most of the previous studies on the effect of the length of feeding period have been done on American and British continental breeds that were fed corn-based diets and pasture grasses, which are abundant in their area. In addition, most of the cattle used in these studies were younger than those raised in Asian countries. In 2008, the slaughter age of Hanwoo was increased from 24 mon to 30-32 mon. Although Park et al. (2002) have previously shown that Hanwoo carcasses with heavier weights had higher quality grades than those of lighter weight, their study made use of animals from various production systems and different classes of cattle such as steers, bulls and cows.

Hanwoo are traditionally raised in feedlots and are fed high concentrate corn-based diets and rice straw. The exorbitant price of corn compelled the cattle raisers to explore the use of barley grains and whole-crop barley silage in cattle feeding. The use of barley is expected to decrease the feed cost since the crop is locally grown. The effect of the length of feeding of barley-based diets on the meat quality of Hanwoo steers have not been evaluated yet. This study was conducted to assess the effects of slaughter endpoints (i.e., 26 vs 32 mon) on the carcass characteristics, objective and subjective meat quality traits and fatty acid composition of $m$. longissimus.

\section{Material and Methods}

\section{Animals, experimental design and sampling}

Hanwoo were raised by chosen private feedlot beef cattle raisers. Twenty six steers were weaned at 6 mon of age and were assigned to either one of two feeding strategies: 
short-term or long-term feeding. The short-term group was fed until 26 mon of age while the long-term group was fed until 32 mon of age. Both treatment groups were fed with commercial diets including whole-crop barley silage. The nutrient content of commercial whole-crop barley silage was moisture $33 \%$, crude protein $8 \%$, crude fiber $6 \%$, crude ash $8 \%$, neutral detergent fiber (NDF) $15 \%$ and acid detergent fiber (ADF) $8 \%$ respectively. At the end of the feeding period, 13 animals from each treatment group were slaughtered and chilled for $24 \mathrm{~h}$. Strip loin samples ( $m$. longissimus) were taken from the right side of the carcass. Each loin was divided into two portions, vacuum-packed and was assigned to two ageing groups, $1 \mathrm{~d}$ or $10 \mathrm{~d}$ aging. Ageing was done at $4^{\circ} \mathrm{C}$.

\section{Carcass characteristics}

Carcasses were graded and evaluated by an official grader for carcass traits according to the Korean grading standard (NLCF, 2004) after a $24 \mathrm{~h}$ chill. Sides were cut between the last rib and the first lumbar vertebrae to determine backfat thickness, ribeye area and quality traits. Backfat thickness was determined over the medial third part of the ribeye. Yield index was calculated as follows:

$$
\begin{aligned}
\text { Yield index } & =64.184-[0.625 \times \text { backfat thickness }(\mathrm{mm})] \\
& +\left[0.130 \times \text { ribeye } \operatorname{area}\left(\mathrm{cm}^{2}\right)\right] \\
& -[0.024 \times \text { carcass weight }(\mathrm{kg})]+3.23
\end{aligned}
$$

Yield grade was scored as

3 A grade (yield index $\geq 67.50$ )

2 B grade $(62.00 \leq$ yield index $<67.50)$

$1 \quad \mathrm{C}$ grade (yield index $<62.00$ )

Marbling was scored from 1 (devoid) to 9 (abundant) according to the standard. Meat color was scored from 1 (bright cherry red) to 7 (extremely dark red) while fat color was scored from 1 (white) to 7 (dark yellow) according to standard. Firmness was scored from 1 (firm) to 3 (soft) according to the reference index. Maturity was based on the ossification of the cartilage in the left semiconductor backbone thorn promontory and was scored from 1 (youthful) to 9 (mature) according to reference index. Carcass quality grade was scored based on marbling score.

\section{Objective meat quality traits}

The Warner Bratzler shear force values were measured in an Instron Universal Testing Machine (Model 3342, Instron Corporation, USA) on six pieces core samples with 0.5 inch diameter using a crosshead speed of 400 $\mathrm{mm} / \mathrm{min}$ and a $40 \mathrm{~kg} \cdot \mathrm{f}$ load cell.

Meat color evaluation was done with Konica Minolta Spectrophotometer CM-2500d (Sinodevices Group, Japan) with an $8 \mathrm{~mm}$ measuring port, D 65 illuminant and $10^{\circ}$ observer. Three measurements were taken on the bloomed surface of the meat and the CIE L* $a^{*} b^{*}$ values were determined. The data presented are means of three measurements.

Determination of $\mathrm{pH}$ was done in duplicates following the procedure of Bendall (1973). The $\mathrm{pH}$ was measured with an Orion 3 Star (Thermo Electron Corp., USA) pH meter.

The moisture content was measured in duplicates in an HR73 halogen moisture analyzer (Mettler-Toledo GmbH, Switzerland) set at $105^{\circ} \mathrm{C}$. A $2.5 \mathrm{~g}$ minced meat sample was used for each measurement.

The intramuscular fat was analyzed using the Soxhlet method with petroleum ether. Minced $5 \mathrm{~g}$ sample was placed in an extraction thimble, dried at $102^{\circ} \mathrm{C}$ for $5 \mathrm{~h}$, then cooled in dessicator and placed in Soxhlet extractor. The samples were extracted with petroleum ether for $6 \mathrm{~h}$ and kept fat extract for $1 \mathrm{~h}$ in the dry oven at $102^{\circ} \mathrm{C}$ after petroleum ether was evaporated. The crude fat content was quantified as the weight percentage of wet muscle tissue.

Oxidative stability was determined by measuring the thiobarbituric acid reactive substance (TBARS) following the procedure of Buege and Aust (1978). Briefly, a $2.5 \mathrm{~g}$ meat sample with $7.5 \mathrm{~mL}$ distilled water, $25 \mu \mathrm{L}$ saturated butylated hydroxyanisole (BHA) solution and $10 \mathrm{~mL}$ thiobarbituric acid/ trichloroacetic acid (TBA/TCA) solution was homogenized at $11,000 \mathrm{rpm}$ for $15 \mathrm{~s}$ using an Ultra Turrax T25 (IKA Labortechnik, Jkika Works (Asia) Sdn., Bhd., Malaysia). The volume of the homogenate was adjusted to $30 \mathrm{~mL}$ with a TBA/TCA solution and was immediately placed in ice. The tube containing the homogenate was immersed in a $90^{\circ} \mathrm{C}$ water bath for 15 $\mathrm{min}$. Thereafter, it was placed in ice to cool for $20 \mathrm{~min}$. Centrifugation at $3000 \mathrm{rpm}$ for $10 \mathrm{~min}$ was followed. About 1 to $1.5 \mathrm{~mL}$ supernatant was taken and the absorbance was measured at $531 \mathrm{~nm}$ in Ultrospec 2000 spectrophotometer (Pharmacia Biotech, Cambridge, England). The TBARS value was calculated by multiplying the absorbance reading by 5.88 . TBARS was expressed as $\mathrm{mg}$ malonaldehyde/kg meat sample.

\section{Fatty acid analysis and extraction}

Direct transesterification of fatty acid followed the procedure developed by Rule (1997). Thin slices of meat 
sample were freeze-dried for $48 \mathrm{~h}$ and pulverized. Five hundred $\mathrm{mg}$ of dried beef muscle was placed into a 20 $\mathrm{mL}$ headspace vial with silicone-lined cap. This was done in duplicates. Into each vial, $2 \mathrm{~mL}$ of $14 \%$ boron-trifluoride in methanol (BDH, BDH Lab. Supplies, Poole, England) and $2 \mathrm{~mL}$ of methanol (High-pressure Liquid Chromatography (HPLC) grade) were added. The tube was sealed with a scrimp cap before it was placed in a heating block set at $80^{\circ} \mathrm{C}$. The tube was maintained at $80^{\circ} \mathrm{C}$ and vortexmixed every $5 \mathrm{~min}$ for $2 \mathrm{~h}$. Cooling of the tubes soon followed and thereafter, $3 \mathrm{~mL}$ distilled water and $3 \mathrm{~mL}$ hexane were added. The tubes were capped and vortex-mixed for $15 \mathrm{~s}$. Centrifugation at $1000 \mathrm{~g}$ force for $5 \mathrm{~min}$ was done to accelerate phase separation. One $\mathrm{mL}$ of the upper hexane phase was transferred to GLC auto-sampler vials and was sealed. The extract was stored at $-20^{\circ} \mathrm{C}$ if gas chromatography will not be done immediately.

Gas chromatograph Agilent Technologies 6890N Network GC System equipped with Agilent Technologies 7683B Series Injector and Agilent Technologies 5973 Network Mass Selective Detector was used to separate and identify the fatty acid components of the samples. GC separation of components was carried out on a fused silica capillary column $(30 \mathrm{~m} \times 0.25 \mathrm{~mm} \times 0.25 \mu \mathrm{m}$ film thickness, Supelcowax 10). Split ratio used was 100:1. Helium was used as the carrier gas. The inlet temperature was $250^{\circ} \mathrm{C}$ and the oven temperature program used was as follows: $50^{\circ} \mathrm{C}$ for $1 \mathrm{~min}$, raise the temperature to $200^{\circ} \mathrm{C}$ at the rate of $25^{\circ} \mathrm{C}$ per minute, further increase the temperature to $230^{\circ} \mathrm{C}$ at $3^{\circ} \mathrm{C}$ per min. The temperature was held at $230^{\circ} \mathrm{C}$ for $15 \mathrm{~min}$. Detector temperature was $280^{\circ} \mathrm{C}$. Total running time was $35 \mathrm{~min}$. Individual fatty acids were expressed as percentage of the total fatty acids detected as fatty acid methyl esters.

\section{Sensory Evaluation}

The sensory evaluation of the beef samples was done following the Yakiniku protocols developed by (Cho et al., 2007). Sensory evaluation was done by a consumer panel consisted of university students. Consumer evaluation of the samples was done and the panel consisted of university students. A total of 52 sets of samples were evaluated in four sensory sessions i.e. 12 sets of samples per session. Each session had 12 panelists and each panelist evaluated 6 samples. Each sensory session had different set of consumer panelists.

\section{Sample Preparation}

The vacuum-packed strip loin samples were thawed overnight at $4^{\circ} \mathrm{C}$. The Longissimus dorsi muscle was obtained and one block was taken from the middle portion. The muscle fiber direction followed the length of the block. Ten thin slices $(30 \mathrm{~mm} \times 30 \mathrm{~mm} \times 4 \mathrm{~mm})$ were taken from across the block. The meat strips were immediately placed in the freezer. Out of the total strips from each sample, six strips were chosen and placed back in the freezer. The chosen strips of meat samples were arranged in the labeled plastic, vacuum-packed and immediately placed in the freezer set at $-20^{\circ} \mathrm{C}$.

Sensory evaluation forms, a glass of distilled drinking water, salt-free crackers, knife and fork were provided to the panelists. The beef samples allotted for evaluation were thawed 30 minutes before the scheduled sensory session. The vacuum-packed meat were opened only when the samples are about to be cooked. The meat strips were cooked to medium doneness following the Korean barbecue procedure. Cooking temperature ranged from 250$260^{\circ} \mathrm{C}$. The cooked samples were immediately dispensed on individual plates and served to the panelists. A $10 \mathrm{~cm}$ unstructured line scale with verbal anchors based on quantitative descriptive analysis was used in which the left anchor represented scoring of either not tender, not juicy, extremely dislike the flavor or sample is extremely unacceptable. Sensory attributes were evaluated using a scale of 0 to 100, with 0 representing the left anchor and 10 representing the right anchor.

\section{Statistical analysis}

The data on carcass characteristics were analyzed using the one way analysis of variance. For the objective meat traits, the main effects of the length of feeding and aging period and length of feeding $\times$ aging period interaction were analyzed using SAS PROC GLM (SAS Institute, Cary, NC). The length of feeding $\times$ aging period interaction was not significant for the traits that were measured hence, only the least square means of the two main effects were presented.

\section{Results and Discussion}

\section{Carcass characteristics}

The slaughter age of cattle subjected to short-term and long-term feeding of whole-crop barley diets were 26 and 32 mon, respectively. Average live weight at slaughter was $633.5 \mathrm{~kg}$ for the short-term fed group and $701.7 \mathrm{~kg}$ for the long-term group (Data not shown). The carcass traits of Hanwoo cattle from different feeding systems are shown in Table 1. Carcass weight, ribeye area, yield 
Table 1. Carcass characteristics of highly marbled Hanwoo steers subjected to different feeding length

\begin{tabular}{|c|c|c|c|c|}
\hline \multirow{2}{*}{ Traits } & \multicolumn{2}{|c|}{ Feeding length } & \multirow{2}{*}{ SEM $^{1)}$} & \multirow{2}{*}{$\mathrm{F}$ value } \\
\hline & 26 mon & 32 mon & & \\
\hline \multicolumn{5}{|l|}{ Yield traits } \\
\hline Carcass weight (kg) & 364 & 407 & 9.73 & $15.34 * *$ \\
\hline Back fat (mm) & 10.6 & 9.7 & 1.05 & 0.54 \\
\hline Rib-eye area $\left(\mathrm{cm}^{2}\right)$ & 82.2 & 90.5 & 2.68 & $7.79 * *$ \\
\hline Maturity ${ }^{2)}$ & 2 & 2 & - & - \\
\hline Yield index ${ }^{3)}$ & 65.4 & 68.6 & 0.93 & $3.41 *$ \\
\hline Yield grade ${ }^{4)}$ & 2 & 3 & 0.21 & $3.76^{*}$ \\
\hline \multicolumn{5}{|l|}{ Quality traits } \\
\hline Marbling score ${ }^{5)}$ & 4 & 6 & 0.38 & $63.0^{* * *}$ \\
\hline Meat color ${ }^{6)}$ & 5 & 5 & - & - \\
\hline Fat color ${ }^{7)}$ & 2.8 & 3 & 0.11 & 0.46 \\
\hline Texture $^{8)}$ & 1.4 & 1 & 0.09 & $10.7 * *$ \\
\hline Quality grade ${ }^{9)}$ & 3 & 4 & 0.25 & $44.5^{* *}$ \\
\hline
\end{tabular}

${ }^{1)}$ SEM: Standard error of the means

${ }^{2)}$ Maturity score was scored from 1 (youthful) to 9 (mature).

${ }^{3)}$ Yield index $=64.184-[0.625 \times$ backfat thickness $(\mathrm{mm})]$ $+\left[0.130 \times\right.$ ribeye area $\left.\left(\mathrm{cm}^{2}\right)\right]+3.23$.

${ }^{4)}$ Yield grade was scored as: 1, C grade (yield index $<62.00$ ); 2, B

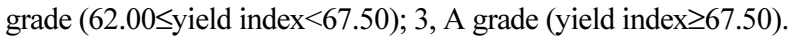

${ }^{5)}$ Marbling score: 1 (devoid) to 9 (abundant).

${ }^{6}$ Meat color score: 1 (bright cherry red) to 7 (extremely dark red).

${ }^{7)}$ Fat color score: 1 (white) to 7 (dark yellow).

${ }^{8)}$ Firmness score: 1 (firm) to 3 (soft).

${ }^{9)}$ Quality grade was scored as: 1, 3 grade (marbling score no.1); 2, 2 grade (marbling score no. 2 or 3); 3,1 grade (marbling score no. 4 or 5 ); $4,1^{+}$(marbling score no. 6 or 7 ); $5,1^{++}$(marbling score no. 8 or 9 ).

${ }^{*} p<0.05,{ }^{* *} p<0.01, * * * p<0.001$.

index and yield grade were significantly higher $(p<0.05)$ in the long-term fed than in the short-term fed. These can be attributed to the higher live weight of the 32 mon old cattle. The current results were in agreement with the findings of Park et al. (2002) who reported that yield grade of Hanwoo cattle improved with increased animal weight and that yield grade and ribeye area are positively correlated ( $\mathrm{r}=0.51)$. However, Park et al. (2002) observed that there was no further increase in yield for cattle weighing more than $551 \mathrm{~kg}$. This is because the cattle that they evaluated within live weight classes were a mixture of steers, bull and cows that are of different ages. In the present study, steers of almost similar ages were used. In contrast, Moon et al. (2006) did not observe significant differences in carcass weight and yield grade of Hanwoo cow from different maturity groups classified as: young, intermediate and old). In the same study, cattle in the young and the intermediate group had higher ribeye area than the old cattle group.

Most carcass traits of British Continental crossbreds (Camfield et al., 1997; Van Koevering et al., 1995), Angus $\times$ Hereford (Duckett et al., 1993; May et al., 1992), Limousin, Hereford, Shorthorn, Longhorn cross and Simmental cross (Williams et al., 1989), Angus (Greene et al., 1989), Simmental (Miller et al., 1987) and Hereford (Dinius and Cross, 1978) steers fed with high concentrate finishing diets increased with days on feed. Slaughter age in the cited studies ranged from 12 to 23 mon. Okumura et al. (2007) revealed that the increase in carcass weight of Japanese Black cattle from 24 to 30 mon of age is characterized by proportional increases in the weights of principal muscles like M. longissimus.

The results of the current experiment indicate that lean deposition still occurs in Hanwoo until 32 mon of age and that the energy density of the barley diets used was sufficient to support the growth of the animals. Bowling et al. (1978) have demonstrated that as age of cattle increase, the rate of protein production decrease, however, the decrease was less in management systems which utilized feedstuffs with a greater concentration of energy. In their study, 2 years old Santa Gertrudis steer calves fed grains produced greater quantities of protein than their grass-fed counterpart.

Marbling score was almost two times higher in beef from the long-term fed group than in beef from the shortterm fed group (6.08 vs. 4.23$)$ hence, quality grade of the former was significantly higher $(p<0.005)$. This demonstrated that intramuscular fat deposition occurs in Hanwoo steers until 32 mon of age. This is substantiated by our findings that intramuscular fat content was significantly higher $(p<0.01)$ in the long-term fed group than in the short-term fed cattle. Chung et al. (2000) that adipocyte diameter in subcutaneous, intermuscular and perirenal fat tissues continuously increased from 15 to 30 mon of age in Hanwoo bulls. In addition, feeding level of concentrates did not affect lipogenesis and adipocyte size of the adipose tissues. Adipocyte diameter and number of adipocyte cells per gram intramuscular and subcutaneous tissue of Angus steers fed either a low or a high concentrate corn-based diet from 8 mon to 16-18 mon of age were similar (Smith and Crouse, 1984). Moreover, age and diet had no effect on the activities of ATP-citrate lyase and NADP-malate dehydrogenase, enzymes involved in lipogenesis, in the intramuscular adipose tissue of the Angus steers. The results of the present study indicate that Hanwoo steers have a great propensity for intramuscular fat deposition and that the process occurs until the later stage of the fattening period. Okumura et al. (2007) reported that additional fattening period of 6 mon from 24 to 30 mon in Japanese Black steers resulted in an increase in 
intramuscular fat of $\mathrm{m}$. longissimus. The percentages of carcasses achieving the greatest meat quality grade as assessed by the Japanese Meat Grading Association were $25 \%$ at 24 mon and $75 \%$ at 30 mon of age. Van Koevering et al. (1995) stated that the point of optimum marbling may vary with genetics and mature size. The Japanese Black cattle, an early-maturing beef breed, are characterized by an ability to deposit much intramuscular fat (Xie et al., 1996) and this explains the continued increase in intramuscular fat deposition during the later phase of growth (24-30 mon of age). In addition, Scollan et al. (2006) pointed out that the development of intramuscular fat content is late maturing. It is due to maintained or increased fat synthesis in combination with declining muscle growth as animals get older. These may partly explain the present findings that deposition of intramuscular fat in Hanwoo m. longissimus occurred until 32 mon of age.

The high energy content of the finishing concentrate diet given to steers in the current experiment may have contributed to the increased marbling score of the Longissimus muscle. The major nutritional tool for increasing the development of marbling is to maximize the availability of net energy and glucose for fat synthesis during finishing (Scollan et al., 2006). This is because glucose contributes a greater proportion of carbon to fatty acid biosynthesis in intramuscular adipose tissue (Hausman et al., 2009).

Hausman et al. (2009) stated that in many breed types, there is a nearly linear increase in marbling or intramuscular fat with time on a finishing diet. However, a number of studies have revealed that intramuscular fat deposition proceeds in a non-linear manner. The optimum marbling score was attained after 119 d (Van Koevering et al., 1995), 112 d (Duckett et al., 1993; May et al., 1992; Williams et al., 1989), $84 \mathrm{~d}$ (Greene et al., 1989) and $240 \mathrm{~d}$ (Zinn et al., 1970) on high-concentrate feed. The cattle in the mentioned studies had initial live weights of $224-350 \mathrm{~kg}$, initial age of 8-16 mon and 17 to 20 mon slaughter age. These were younger than the Hanwoo in the current experiment.

The quality grade of the long-term fed cattle was significantly higher $(p<0.01)$ than the short-term fed group in the present experiment and this can be attributed to the high marbling score of carcasses from the long-term fed group. Moon et al., (2003) reported a strong relationship $(\mathrm{r}=0.81)$ between quality grade and marbling score. On this basis, the quality grading system in Korea is primarily determined by marbling and additionally adjusted by carcass traits such as meat color, fat color, texture and maturity (Moon et al., 2006).

Maturity, backfat thickness, fat color and lean meat color and scores did not differ between the short-term and the long-term fed cattle. Similar maturity scores were obtained by cattle from the two feeding groups indicating that the 6 mon age difference does not influence the physiological maturity of Hanwoo. The maturity score of the carcass is based on the color, shape and ossification of the bones and cartilages (Kim and Lee, 2003). Conversely, the lack of any significant difference in the meat and fat color scores may be due to similar level of maturity of the carcasses from the short-term and the long-term fed steers. Moon et al. (2006) observed similar meat color scores among Hanwoo cow carcasses with different maturity whereas, fat color scores differed significantly. Kim and Lee (2003) noted no significant differences in the mean lean color, fat color and maturity scores among Hanwoo cow carcasses of different quality grades. The longissimus muscle from the long-term fed group tended to be more firm $(p<0.05)$ than the short-term fed group. This is due to higher marbling of beef from cattle fed up to 32 mon of age. The chilled intramuscular fat tended to increase the firmness of raw meat. McBee and Wiles (1967) observed that carcasses with higher degrees of marbling were significantly firmer than those with lower marbling. Similar results were obtained by Kim and Lee (2003) in which Hanwoo carcasses with high quality grade were assessed to be more firm.

\section{Objective and subjective meat quality traits}

The objective meat quality traits of M. longissimus of Hanwoo steers are presented in Table 2. Both feeding system and ageing influenced the WBSF value of the beef. Beef from steers belonging to the long term- fed group had significantly lower WBSF value (2.92 vs. $3.61 \mathrm{~kg})$ than beef from steers in the short term-fed group. Similar findings were obtained by Moon et al. (2006) who reported that WBSF values was highest $(p<0.05)$ for low marbling group when it was compared to high and intermediate marbling groups of Hanwoo beef females. Furthermore Nishimura et al. (1999) reported that for Japanese black steers that were finished on concentrates with corn silage and orchard grass hay from 9 mon to 32 mon of age, the increase in crude fat content of the longissimus muscle caused a decrease in WBSF value indicating an improvement in the tenderness of the meat. It was observed that highly developed adipose tissues in longissimus muscle disorganize the structure of the intramuscular connective tissue and bring about a weakening of the intramuscular 
Table 2. Objective meat quality traits of highly marbled Hanwoo steers subjected to different feeding length and different ageing periods

\begin{tabular}{|c|c|c|c|c|c|c|c|c|}
\hline \multirow{2}{*}{ Traits } & \multicolumn{2}{|c|}{ Feeding length } & \multicolumn{2}{|c|}{ Ageing } & \multirow{2}{*}{$\mathrm{SEM}^{1)}$} & \multicolumn{3}{|c|}{ F value } \\
\hline & 26 mon & 32 mon & $1 \mathrm{~d}$ & $10 \mathrm{~d}$ & & Feeding & Ageing & Feeding*Ageing \\
\hline Moisture (\%) & 52.5 & 51.5 & 52.2 & 53.8 & 1.25 & 0.42 & 1.57 & $4.89 *$ \\
\hline IMF (\%) & 14.4 & 20.7 & - & - & 1.89 & $2.6^{*}$ & - & - \\
\hline $\mathrm{pH}$ & 5.54 & 5.51 & 5.53 & 5.52 & 0.02 & 3.86 & 0.02 & 0.01 \\
\hline WBSF (kg) & 3.6 & 2.9 & 3.27 & 2.71 & 0.22 & $2.26^{*}$ & $6.17 *$ & 1.64 \\
\hline Cooking loss (\%) & 18.3 & 16.5 & 17.9 & 16.7 & 0.54 & $5.03 *$ & 1.59 & 2.79 \\
\hline CIE L* & 34.4 & 37.3 & 35.7 & 38.8 & 1.05 & $6.02 *$ & $8.96^{* *}$ & 2.39 \\
\hline CIE a* & 16.6 & 16.9 & 16.8 & 18.6 & 0.54 & 0.46 & $12.8^{* *}$ & 2.18 \\
\hline CIE b* & 13.8 & 12.5 & 13.1 & 15.3 & 0.44 & 0.05 & $28.2 * * *$ & 0.24 \\
\hline TBARS (mg MA/kg) & 0.25 & 0.32 & 0.29 & 0.31 & 0.03 & $6.9^{*}$ & 0.26 & 0.25 \\
\hline \multirow{2}{*}{ Trait } & \multicolumn{2}{|c|}{ Short } & \multicolumn{2}{|c|}{ Long } & \multirow{2}{*}{ SEM } & \multicolumn{3}{|c|}{$\mathrm{F}$ value } \\
\hline & $1 \mathrm{~d}$ & $10 \mathrm{~d}$ & $1 \mathrm{~d}$ & $10 \mathrm{~d}$ & & \multicolumn{3}{|c|}{ Feeding*Ageing } \\
\hline Moisture (\%) & 53.2 & 52.6 & $54.3 \mathrm{~b}$ & $51.3 \mathrm{a}$ & 1.25 & \multicolumn{3}{|c|}{$4.89 *$} \\
\hline
\end{tabular}

${ }^{1)}$ SEM: Standard error of the means

${ }^{*} p<0.05,{ }^{*} p<0.01, * * * p<0.001$.

connective, contributing to tenderization of highly marbled beef. Miller et al. (1987) observed that Simmental steers backgrounded on high energy diet produced fatter carcasses with high marbling score, high quality grade and more tender meat. Similarly, Bowling et al. (1977) observed that heavier, fatter carcasses produced more tender steaks than thinner and lighter carcasses. Moreover, May et al. (1992) stated that days on feed and carcass grade traits affect tenderness by delaying carcass chilling rate and enhancing early postmortem muscle temperature thereby, meat toughening due to cold shortening is prevented. Several researches have indicated that tenderness tended to increase with increased time on feed but only to a limited extent because age of the animal also exerts an influence. Zinn et al. (1970) attained the lowest shear force value of muscle tissue from Hereford steers and heifers at $180 \mathrm{~d}$ on feed at an average age of $430 \mathrm{~d}$. In their study, the cattle were started on the treatment diets at an average age of $250 \mathrm{~d}$. Additionally longissimus muscle was more tender at 150,180 and $210 \mathrm{~d}$ on feed, which is equivalent to 400 to $450 \mathrm{~d}$ of age of the animal.

In the present experiment, strip loin aged for $10 \mathrm{~d}$ had significantly lower $(p<0.05) \mathrm{WBSF}$ value $(2.71$ vs. 3.27 $\mathrm{kg}$ ) than those chilled for one day. Similar findings were obtained by Kim and Lee (2003) who observed that decreased the WBSF value of loin from Hanwoo cows when increased postmortem aging (1-14). It has been an established fact that ageing improves tenderness through proteolytic enzyme activities on meat proteins (Koohmarie, 1996). Moreover Miller et al. (2001) categorized tender, intermediate and tough steaks as having less than
$3 \mathrm{~kg}(29.43 \mathrm{~N})$, between $3 \mathrm{~kg}(29.43 \mathrm{~N})$ and $4.6 \mathrm{~kg}(45.13$ $\mathrm{N})$, and greater than $4.6 \mathrm{~kg}(45.13 \mathrm{~N})$ of shear force, respectively.

Cooking loss significantly lower $(p<0.05)$ in Hanwoo steers belonging to long term feeding group. Similar findings were by Moon et al. (2006) noted that significant difference on the cooking loss of beef belonging to different marbling score in which beef with higher marbling had lower cooking loss. Van Koevering et al. (1995) observed that cooking loss of the longissimus muscle from British $\times$ Continental steers, $329 \mathrm{~kg}$ initial weight, decreased with increased time on high concentrate feed with lower cooking losses attained beyond $105 \mathrm{~d}$ of feeding. However cooking loss did not differ in Hanwoo cows belonging to different quality grade groups (Kim and Lee, 2003) and different maturity groups (Moon et al., 2006).

Both feeding system and ageing period did not influence the pHu. Similar results were by Kim and Lee (2003); Han et al. (1996) reported that $\mathrm{pH}$ values of quality grade groups from Hanwoo beef were not significantly differed. Moreover they reported that the $\mathrm{pH}$ measurements alone can be used to follow glycolytic changes in muscles, twentyfour hours postmortem, when glycolysis is considered to be complete, the $\mathrm{pH}$ values were the same in all quality groups.

Strip loin steaks from the long-term and short-term group had similar CIE a* value however CIE L* CIE b* values significantly differed. These changes in muscle lightness and yellowness were attributed to dietary effects on marbling levels (Kim and Lee, 2003). This explanation applies to the current findings that the $\mathrm{m}$. longissimus 
Table 3. Sensory attributes of highly marbled Hanwoo steers subjected to different feeding system and subjected to different ageing period

\begin{tabular}{|c|c|c|c|c|c|c|c|c|}
\hline \multirow{2}{*}{ Traits } & \multicolumn{2}{|c|}{ Feeding length } & \multicolumn{2}{|c|}{ Ageing } & \multirow{2}{*}{ SEM $^{1)}$} & \multicolumn{3}{|c|}{ F value } \\
\hline & 26 mon & 32 mon & $1 \mathrm{~d}$ & $10 \mathrm{~d}$ & & Feeding & Ageing & Feeding*Ageing \\
\hline Tender $^{2)}$ & 50.1 & 54.7 & 52.6 & 66.1 & 3.35 & 3.60 & $17.56 * *$ & 0.11 \\
\hline Juicy $^{3)}$ & 64.5 & 71.5 & 68.3 & 69.4 & 2.37 & $8.44^{*}$ & 0.50 & $4.03 *$ \\
\hline Flavor ${ }^{4)}$ & 62.3 & 67.3 & 61.9 & 63.3 & 2.55 & 0.16 & 0.39 & 1.35 \\
\hline Overall acceptability ${ }^{5)}$ & 55.3 & 60.5 & 56.7 & 65.8 & 3.88 & $4.46^{*}$ & $9.71 * *$ & 0.15 \\
\hline Rating $^{6}$ & 1.8 & 2.2 & 1.9 & 2.3 & 0.17 & $9.61 *$ & $9.60 *$ & 0.02 \\
\hline \multirow{2}{*}{ Trait } & \multicolumn{2}{|c|}{ Short } & \multicolumn{2}{|c|}{ Long } & \multirow{2}{*}{ SEM } & \multicolumn{3}{|c|}{ F value } \\
\hline & $1 \mathrm{~d}$ & $10 \mathrm{~d}$ & $1 \mathrm{~d}$ & $10 \mathrm{~d}$ & & \multicolumn{3}{|c|}{ Feeding*Ageing } \\
\hline Juicy & $62.8 \mathrm{a}$ & $68.4 b$ & 72.9 & 70.3 & 2.62 & \multicolumn{3}{|c|}{$4.03 *$} \\
\hline
\end{tabular}

${ }^{1)}$ SEM: Standard error of the means

${ }^{2)}$ Tenderness rating: 0 (not tender) to 100 (very tender).

${ }^{3)}$ Juiciness rating: 0 (not juicy) to 100 (very juicy).

${ }^{4)}$ Flavor rating: 0 (dislike extremely) to 100 (like extremely).

${ }^{5)}$ Overall acceptability: 0 (dislike extremely) to 100 (like extremely).

${ }^{6)}$ Rating: 1, unsatisfactory; 2 , good everyday quality; 3 , better than everyday quality; 4, premium quality. $* p<0.05, * * p<0.01, * * * p<0.001$.

from the 32 mon old steers which has higher marbling score than 26 mon. Furthermore Lynch et al. (2002) reported that feeding effects on color were attributed to the relationship between lipid and pigment oxidation, particularly the instability of polyunsaturated fatty acids.

On the other hand, all the color parameters were significantly higher in the $10 \mathrm{~d}$ aged beef than the $1 \mathrm{~d}$ beef implying a brighter red color in the $10 \mathrm{~d}$ beef. Joseph and Connolly (1970) explained that the increase in lightness (CIE L* value) of meat during ageing is due to the modification of protein structures thus giving a higher dispersion of light. A $10 \mathrm{~d}$ ageing period at $4^{\circ} \mathrm{C}$ used in the present experiment was sufficient to cause some changes in muscle protein thus a higher CIE L* value was obtained. In addition Gasperlin et al. (2001) reported that ageing could also increase the permeability of the sarcolema to myoglobin as a result of all these changes the differences between color parameters can be explained by the changed physical parameters of the meat i.e. the different absorption, transmission and reflection characteristics of the surface of the meat.

Change in the color of meat during ageing is partially influenced by the type of muscle. McKenna et al. (2005) classified the M. longissimus lumborum under the "high" color stability muscle group. The group is characterized by a high resistance to induced metmyoglobin formation. This finding may explain the high color parameters of the strip loin after $10 \mathrm{~d}$ aging. Similarly, Boakye and Mittal (1996) concluded that time of ageing affects all instrumental parameters of color CIE L*, $a^{*}, b^{*}$ values. Lee et al. (2008) observed a more vivid, redder and more yellow color of gluteus medius steaks that were aged for $14 \mathrm{~d}$ or less compared to the steaks that were aged for longer periods. Moreover Irurueta et al. (2008) have demonstrated that the color of the M. longissimus dorsi of buffalo grazed in pastures was affected by aging time. The lightness (CIE L*) parameter increased significantly at 25 $\mathrm{d}$ postmortem while red index (CIE $\mathrm{a}^{*}$ ) and yellow (CIE $\mathrm{b}^{*}$ ) decreased at $15 \mathrm{~d}$ and $25 \mathrm{~d}$ postmortem, respectively. In comparison, changes in color parameters in the current experiment occurred within $10 \mathrm{~d}$ ageing. The differences on the ageing period when color changes occurred may be ascribed to the feeding regime and the animal species used. Irurueta et al. (2008) evaluated the meat color of 2024 mon old water buffalos that were grown on pasture.

Oxidative stability (TBARS value) was significantly influenced by the feeding system. Oxidative stability was lower in beef from the long term fed-group as indicated by the significantly higher TBARS value $(p<0.05)$ than the beef from the short term-fed group (0.32 vs. 0.25 ). This can be attributed to the higher intramuscular fat content of the beef from the long term-fed group indicating that the quantity of fatty acids that had undergone oxidation was higher. Less saturated fat containing a number of fatty acids with double bonds are easily oxidized, either by direct chemical action or through intermediary activity of lipolytic enzymes (Webb and O'Neill, 2008). The rate of autooxidation increases with the number of double bonds. Elmore et al. (2000) had suggested that oxidized n-3 PUFA initiate the oxidation of the more abundant 
unsaturated fatty acids like the C18:2n-6.

TBARS values of the $1 \mathrm{~d}$ and $10 \mathrm{~d}$ beef did not differ significantly. Each aging group had a mixture of beef samples obtained from both the short-term and the longterm fed group thus resulting in almost similar average TBARS value for $1 \mathrm{~d}$ and $10 \mathrm{~d}$. The TBARS values of the strip loin in the current experiment were below the critical limit of $0.5 \mathrm{mg} \mathrm{MAL} / \mathrm{kg}$ meat. Values above 0.5 indicate a level of lipid oxidation products which impart a rancid flavor and odor that can be detected by consumers (Wood et al., 2008). The findings of the present experiment demonstrate that ageing for $10 \mathrm{~d}$ of strip loin from 32 mon old Hanwoo cattle does not result in excessive oxidation of lipids as to adversely affect meat quality. Kim et al. (2000) observed a gradual increase in the TBARS values of Hanwoo longissimus dorsi muscle during the first $14 \mathrm{~d}$ of postmortem ageing and the sharp increase in TBARS was observed after $14 \mathrm{~d}$.

Feeding system significantly influenced juiciness $(p<$ 0.01 ) with the beef from the long term-fed group having higher juiciness scores than the short term-fed group. The difference in juiciness could be due to the higher intramuscular fat content of the strip loin from long term fedcattle. Muscles having a high content of intramuscular fat tend to have a high WHC. The exact reason is unknown but it was postulated that the intramuscular fat loosens up the microstructure of the muscle, thus allowing more water to be entrained (Lawrie and Ledward, 2006). Similarly, Jeremiah et al. (2003) have observed that fatter meat cuts sustained lower thaw-drip and total cooking loss. The same researchers have determined that fat is highly correlated ( $\mathrm{r}=0.62)$ with juiciness of major beef muscles and muscle groups. Wood et al. (2008) ascribed the increased juiciness with increasing levels of marbling fat to the greater retention of water in meat during cooking. This was demonstrated in the current study in which the strip loin from the long term-fed cattle had numerically lower cooking loss than those from the short term-fed group.

In a review, Blumer (1963) mentioned that a portion of juiciness attributable to beef fat must come from the fatty acids since only $10 \%$ of beef fat is water. The fatty acids that melt at or below the temperature that meat is eaten would contribute to juiciness and these include oleic, linoleic, linolenic and fatty acid with longer chain length. In addition, at least some of the saturated fatty acid fraction would be soluble in the unsaturated fraction. In the current study, the strip loin samples in the long term-fed group characterized by high intramuscular fat content had more melted fat during cooking at $250^{\circ} \mathrm{C}$ thus resulting in higher consumer perception of juiciness. In addition, the high intramuscular fat content in the long term-fed steers exerted a greater stimulatory effect on salivation thereby, sustained juiciness contributed to the greater juiciness scores of M. longissimus. In a more recent experiment, Jeremiah et al. (2003) was able to determine that intramuscular fat accounted for $38.4 \%$ of the variation in the panel juiciness ratings of major beef muscles.

On the contrary, May et al., (1992), Burson et al. (1980) and Dinius and Cross (1978) observed that juiciness was not affected by the time on high concentrate finishing feed. In the experiment of May et al. (1992), longissimus muscles from 16 to 23 mon old Angus $\times$ Hereford steers were broiled to an internal temperature of $70^{\circ} \mathrm{C}$ and were assessed by trained sensory panel. On the other hand, Burson et al. (1980) evaluated oven broiled loin steaks $\left(66^{\circ} \mathrm{C}\right.$ cooked temperature) from Angus yearling steers weighing $352-485 \mathrm{~kg}$. The cattle were finished under different nutritional regimen i.e. diets with different energy density and given at different length of feeding period. Carcass fatness and quality grade increased with extended periods on finishing feed however, panel scores on juiciness did not differ. The difference in their results and our results could have been caused by the type of sensory panel employed to evaluate the beef samples. Sensory assessment was done by consumer panel in our experiment.

The length of the feeding period significantly influenced on the sensory rating scores $(p<0.05)$ and numerically influenced on tenderness, flavor and overall acceptability based on consumer panel assessment in the current study. Similar findings were obtained by Epley et al. (1968) on the consumer assessment of short loin from Angus $\times$ Hereford crossbreds; trained panel assessment revealed that the length of time on feed influenced flavor, tenderness and overall desirability. Camfield et al. (1997), Tatum et al. (1980), Bowling et al. (1978) observed that increased time on high-concentrate feed improved flavor intensity and overall palatability of beef. They attributed this to the positive relationship between intramuscular fat and flavor intensity. In the present experiment, the high intramuscular fat content of loin from the long term-fed group did not influence the tenderness, flavor and overall acceptability. It could be that the sensory profile of the strip loin has been established at 26 mon of age of the cattle and a 6 mon extension in feeding of barley-based diet did not significantly influence the consumer perception of tenderness, flavor and overall acceptability. Duckett et al. (1993) observed that extending the feeding period of 16 mon old 
Angus $\times$ Hereford steers beyond $112 \mathrm{~d}$ did not enhance the palatability characteristics of beef. Some other researchers have shown that juiciness and flavor intensity were not influenced by the time on concentrate feed (May et al., 1992; Burson et al., 1980; Dinius and Cross, 1978).

Ageing significantly improved tenderness $(p<0.001)$, overall acceptability $(p<0.005)$ and rating $(p<0.01)$ of the strip loin. The $10 \mathrm{~d}$ steaks had higher tenderness, overall acceptability and rating scores than the $1 \mathrm{~d}$ steaks indicating the positive influence of tenderness on the acceptability and rating of beef. This supports the survey report of Huffman et al. (1996) that most consumers identified tenderness as the attribute that contributes most to eating satisfaction. The significant increase in tenderness is as expected since a number of researches have demonstrated that the greatest improvement in tenderness occurred during the first few days of ageing. The major increase in tenderness was observed between 1 and $14 \mathrm{~d}$ (Monson et al., 2005) and first $7 \mathrm{~d}$ (Brewer and Novakofski, 2008) of aging. Brewer et al. (2007) observed that increasing ageing time improved tenderness regardless of production system, however ageing had no significant effects on flavor and overall acceptability of steaks from calf-finished or yearling-finished cattle. This supports the current findings that ageing the strip loin for $10 \mathrm{~d}$ had no effect on juiciness and flavor. The absence of a significant difference in the juiciness of strip loin from the $1 \mathrm{~d}$ and the 10 $\mathrm{d}$ ageing groups could be due to the method of ageing used. The wet method of ageing in which the strip loin were vacuum-packed before storing at $4^{\circ} \mathrm{C}$ prevented evaporation of moisture from the meat. This was substantiated by the almost similar moisture content of the $1 \mathrm{~d}$ and the $10 \mathrm{~d}$ loin samples. On the other hand, the almost similar fatty acid profile of strip loin from the long termfed and short term-fed cattle could be attributed for the lack of difference in the flavor of the beef samples. Many compounds that contribute to the smell and flavor are lipid breakdown products. The effect of fatty acid on meat flavor is due to the production of volatile, odorous, lipid oxidation products during cooking and the involvement of these with Maillard reaction products to form other volatiles which contribute to odor and flavor (Wood et al., 2003). The findings of the present experiment indicate that fatty acid composition had a greater influence on flavor than the intramuscular fat content.

The findings of the this study agree with Laster et al. (2008) who observed that ageing method and ageing period had no effect on consumer sensory attributes like flavor and juiciness of beef having US choice and US select grades. In contrast, French et al. (2001) reported that postmortem ageing improved sensory profiles of carcasses from Limousin and Charolais crossbred steers $(567 \mathrm{~kg})$ grazed on ryegrass and given different levels of concentrate feed.

The findings on the sensory traits of Hanwoo strip loin indicate that feeding high concentrate and whole crop barley silage diet positively influences juiciness and rating without affecting tenderness, flavor and overall acceptability. Ageing significantly improved tenderness and overall acceptability and rating scores.

\section{Fatty acid composition}

There were only palmitic acid (C16:0) and linoleic acid (C18:2n6) significantly differed between feeding groups while no significant differences on the other individual

Table 4. Fatty acid content of highly marbled Hanwoo steers subjected to different feeding length and ageing periods

\begin{tabular}{|c|c|c|c|c|}
\hline \multirow{2}{*}{ Fatty acids - } & \multicolumn{2}{|c|}{ Feeding length } & \multirow{2}{*}{ SEM $^{1)}$} & \multirow{2}{*}{ F value } \\
\hline & 26 mon & 32 mon & & \\
\hline $\mathrm{C} 14: 0$ & 4.28 & 3.76 & 0.28 & 2.21 \\
\hline $\mathrm{C} 15: 0$ & 0.36 & 0.33 & 0.04 & 0.01 \\
\hline C16:0 & 26.44 & 24.58 & 0.54 & $2.16^{* *}$ \\
\hline C161:n7 & 5.12 & 5.00 & 0.25 & 0.02 \\
\hline C18:0 & 12.72 & 13.36 & 0.57 & 0.01 \\
\hline C18:1 & 47.02 & 48.12 & 0.81 & 0.02 \\
\hline C18:2n6 & 2.26 & 3.02 & 0.29 & $3.29^{*}$ \\
\hline C18:3n3 & 0.39 & 0.12 & 0.12 & 0.94 \\
\hline C20:0 & 0.19 & 0.15 & 0.05 & 1.8 \\
\hline $\mathrm{C} 20: \ln 9$ & 0.43 & 0.46 & 0.04 & 0.02 \\
\hline $\mathrm{C} 20: 3 \mathrm{n} 3$ & 0.19 & 0.18 & 0.03 & 0.31 \\
\hline $\mathrm{C} 20: 4 \mathrm{n} 6$ & 0.37 & 0.33 & 0.06 & 0.48 \\
\hline $\mathrm{SFA}^{2)}$ & 43.87 & 42.11 & 0.8 & 1.46 \\
\hline MUFA $^{3)}$ & 53.14 & 54.48 & 0.76 & 0.58 \\
\hline PUFA $^{4)}$ & 2.98 & 3.37 & 0.37 & 1.28 \\
\hline PUFA/SFA ${ }^{5)}$ & 0.07 & 0.08 & 0.01 & 1.54 \\
\hline $\mathrm{UFA}^{6)}$ & 56.12 & 57.85 & 0.85 & $\mathrm{~ns}$ \\
\hline UFA:SFA ${ }^{7)}$ & 1.28 & 1.37 & 0.04 & ns \\
\hline$n-6^{8)}$ & 2.63 & 3.35 & 0.28 & ns \\
\hline$n-3^{9)}$ & 0.58 & 0.30 & 0.17 & ns \\
\hline$n-6: n-3^{10)}$ & 4.53 & 11.17 & 2.16 & ns \\
\hline
\end{tabular}

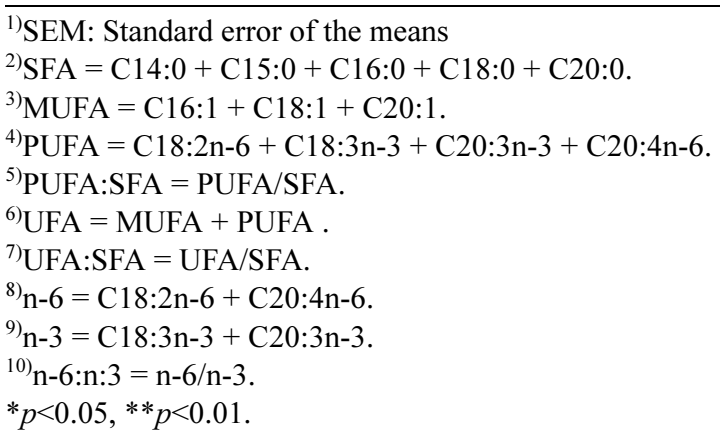


fatty acid component of beef (Table 4). Some studies have also found that the length of feeding had very small influence on the fatty acid composition of beef. Rule et al. (1997) reported that the SFA and MUFA of Longissimus muscle of crossbred steers changed little with time on feed. Sami et al. (2004) observed that feeding intensity had greater influence on the intramuscular fatty acid composition of Simmental bulls compared to the length of feeding. In contrast, several studies have demonstrated that time on feed affects the fatty acid composition of beef. Camfield et al. (1997) reported that as feeding period increased from 0 to $90 \mathrm{~d}$, concentrations of C18:0, C18:2n6, C20:2n-6 decreased while C18:1n-9 increased. In the study of Camfield et al. (1997), the steers were grazed on Bermuda grass for $150 \mathrm{~d}$ before finishing with a highconcentrate diet for $90 \mathrm{~d}$. Duckett et al. (1993) noted an increase in MUFA and a decrease in PUFA of beef from grass-fed steers then fed with high concentrate diets from 0 to 196 d. Marmer et al. (1984) and Rumsey et al. (1972) have reported that time on feed affected fatty acid composition of beef. Differences in fatty acid profile were also observed in cull cows fed concentrate diets for $42 \mathrm{~d}$ (Stelzleni et al., 2008). In most of these studies, it was noted that significant changes in the fatty acid profile occurred during a change in the type of diet given to the animal i.e. from a high forage diet to a high concentrate diet. Rule et al. (1997) reported that the slight modification in the fatty acid profile in their experiment occurred during the first few weeks of feeding which coincided with the transition in the type of diet given to the steers. Mandell et al. (1998) found out differences in the fatty acid profile of Limousin crossbred steers and attributed it to diets used rather than on the length of the feeding period. Mann et al. (2003) pointed out that the type of feeding regime used can influence the lipids in red meat due to the fatty acid composition of the feed. In the current experiment, the steers were fed whole crop barley silage and barley-based concentrate for the entire duration of feeding and this probably explains the similarity in the fatty acid profile of the resulting meat from the two feeding periods. There never was any change in the fatty acid profile of the diet during the experimental period thus the fatty acid profile of the meat was not substantially altered.

Although we observed that there was an increase in fatness in carcasses from steers in the long term-fed group, the fatty acid composition remained relatively the same in the two treatment groups. Skelly et al. (1973) noted that increased unsaturation of fatty acids in meat was associated with marbling. Insausti et al. (2004) reported that the fat/lean ratio as a function of intramuscular fat content is a major factor that influences fatty acid composition. However, Rule et al. (1997) pointed out that as steers grow and fatten, precise metabolic events dictate the nature of the fatty acids and unless synthesis, elongation and desaturation are markedly altered, production of different fatty acid profile is not likely to occur. Differences in genetics and environment (i.e. feeding system) that alter fatty acid metabolism in the animal may cause some differences in the fatty acid profile. A study by Church et al. (1967) have shown that barley and wheat produce fats with a different character such that wheat-fed steers had more C14:0, C16:0 and C16:1 and less C18:0 than did barley-fed animals. Similarly, Wismer et al. (2008) observed higher concentrations of the saturated fatty acids to be higher for barley-fed than for corn-fed steers. This was attributed to the differences in the fatty acid profile of barley and corn. Osman et al. (2000) reported that barley oil contained $22.63 \%$ SFA with palmitic being the principal SFA followed by stearic acid. The unsaturated fatty acid level was about $77.29 \%$ of the total fatty acids, with linoleic acid comprising $39.49-53.40 \%$ of the total amount followed by oleic and linolenic acids. Linolenic acid comprised $10.52 \%$ of the total fatty acid content. In comparison, the total fatty acid of commercial lines of corn is comprised of 59.18 and 1.11 percent linoleic and linolenic acid, respectively (Sidhu et al., 2000). The predominant fatty acids that we obtained in the longissimus muscle of the short term and long term-fed Hanwoo were palmitic (C16:0), stearic (C18:0) and oleic (C18:1). Oleic acid (C18:1) constituted $90 \%$ of the total MUFA. The total fatty acid was comprised of $43 \%$ SFA, $53 \%$ MUFA and $3 \%$ PUFA. Xu et al. (2008) observed that in 26 mon old Hanwoo steers $(644 \mathrm{~kg})$ fed ground concentrate and alfalfa hay on a 9:1 ratio for a 2 mon feeding period, the quantity $(\mathrm{g} / 100 \mathrm{~g})$ of the major fatty acid components of m. longissimus are as follows: C16 (26.49), C16:1 (2.78), C18 (16.77), C18:1n-9 (34.57), C18:2n-6 (6.52), C18:3n3 (0.20). Additionally, SFA, MUFA and PUFA were $49.08,42.84$ and $6.86 \mathrm{~g} / 100 \mathrm{~g}$, respectively. It was noted that the Hanwoo in the study of Xu et al. (2008) had more SFA and C18:2n-6 than the Hanwoo in our experiment. This may be ascribed to the difference in the diet used and the higher proportion of concentrate and roughage given to the animal in the experiment of Xu et al. (2008).

A low PUFA to SFA ratio (0.08-0.09) was obtained in the current study. The results indicate that for 26 and 32 mon old Hanwoo steers fed high concentrate barleybased diets, most of the PUFA are hydrogenated in the 
rumen thus only a small amount of PUFA are deposited in the intramuscular fat of the m. longissimus. The high n-6:n-3 ratio is characteristic of high concentrate-fed cattle. The high content of linoleic acid (C18:2) in barley resulted in more deposition of n- 6 than $n-3$ fatty acids in the m. longissimus.

Given that the collective results of the present study, longer feeding for Hanwoo steers until 32 mon overall improved carcass traits and palatability compared to that for 26 mon. On the other hand, from the viewpoints of economical and environmental aspects, cost of the additional feeding for 6 mon for value-adding of eating quality was relatively high and the effects in turn were limited.

\section{Acknowledgements}

It should be acknowledged that this work was supported by the research grants for the FTA issue project (No. PJ907055), RDA and the research grants for the FTA issue project (No. PJ008525), RDA, Republic of Korea.

\section{References}

1. Bendall, J. R. (1973). Post mortem changes in muscle. In Borne, G. H. (eds) The structure and Functions of Muscle. II. Academic Press, NY, USA, p. 243.

2. Blumer, T. N. (1963) Relationship of marbling to the palatability of beef. J. Anim. Sci. 22, 771-778.

3. Boakye, K. and Mittal, G. S. (1996) Changes in color of beef m. longissimus dorsi muscle during ageing. Meat Sci. 42, 347-354.

4. Bowling, R. A., Smith, G. C., Carpenter, S. L., Dutson, T. R., and Oliver, W. M. (1977) Comparison of forage-finished and grain-finished carcasses. J. Anim. Sci. 45, 209-215.

5. Bowling, R. A., Riggs, J. K., Smith, G. C., Carpenter, Z. L., Reddish, R. L. and Butler, O. D. (1978) Production, Carcass and palatability characteristics of steers produced $\mathrm{b}$ different management systems. J. Anim. Sci. 46, 333-340.

6. Brewer, S. and Novakofski, J. (2008) Consumer sensory evaluations of aging effects on beef quality. J. Food Sci. 73, 78-82.

7. Brewer, P. S., James, J. M., Calkins, C. R., Rasby, R. M., Klopfenstein, T. J., and Anderson, R. V. (2007) Carcass traits and M. longissimus lumborum palatability attributes of calfand yearling-finished steers. J. Anim. Sci. 85, 1239-1246.

8. Buege, J. A. and Aust, J. D. (1978) Microsomal lipid peroxidation. Methods Enzymol. 52, 302-309.

9. Burson, D. E., Hunt, M. C., Allen, D. M., Kastner, C. L., and Kropf, D. H. (1980) Diet energy density and time on feed effects on beef Longissimus muscle palatability. J. Anim. Sci. 51, 875-881.

10. Camfield, P. K., Brown, A. H. Jr., Lewis, P. K, Rakes, L. Y., and Johnson, Z. B. (1997) Effect of frame size and time-on- feed on carcass characteristics, sensory attributes, and fatty acid profiles of steers. J. Anim. Sci. 75, 1837-1844.

11. Cho, S. H., Kim J. H., Seong, P. N., Park, B. Y., Kim, K. E., Seo, G., Lee, J. M., Kim, D. H. (2007) Effect of socio-demographic factors on sensory properties of Korean Hanwoo bull beef by different cut and cooking methods. J. Anim. Sci. Technol. 49, 857-870.

12. Chung, C. S., Kim, N. S., Song, M. K., Choi, Y. I., Woon, Y. S., Chung, J. K., and Kim, J. G. (2000) Effects of age and feeding level of concentrates on adipose tissue lipogenesis and adipocytes size in Hanwoo bulls. Korean J. Anim. Sci. Technol. 42, 459-466.

13. Church, D. C., Ralston, A. T., and Kennick, W. H. (1967) Effect of diet or diethylstilbestrol on fatty acid composition of bovine tissues. J. Anim. Sci. 26, 1296-1301.

14. Dinius, D. A. and Cross, H. R. (1978) Feedlot performance, carcass characteristics and meat palatability of steers fed concentrate for short periods. J. Anim. Sci. 47, 1109-1113.

15. Duckett, S. K., Wagner, D. G., Yates, L. D., Dolezal, H. G., and May, S. G. (1993) Effects of time on feed on beef nutrient composition. J. Anim. Sci. 71, 2079-2088.

16. Elmore, J. S., Mottram, D. S., Enser, M., and Wood, J. D. (2000) The effects of diet and breed on the volatile compounds of cooked lamb. Meat Sci. 55, 149-159.

17. Epley, R. J., Stringer, W. C., Hedrick, H. B., Schupp, A. R., Cramer, C. L., and White, R. H. (1968) Influence of sire and length of feeding on palatability of beef steaks. J. Anim. Sci. 27, 1277-1283.

18. French, P., O'Riordan, E. G., Monahan, F. J., Caffrey, P. J., Mooney, M. T., and Troy, D. J. (2001) The eating quality of meat of steers fed grass and /or concentrates. Meat Sci. 57, 379-386.

19. Gasperlin, L., Lender, B. Z., and Abram, V. (2001) Color of beef heated to different temperatures as related to meat ageing. Meat Sci. 59, 23-30

20. Greene, B. B., Backus, W. R., and Riemann, M. J. (1989) Changes in lipid content of ground beef from yearling steers serially slaughtered after varying lengths of grain finishing. J. Anim. Sci. 67, 711-715.

21. Han, G. D., Kim, D. G., Kim, S. M., Ahm, D. H., and Sung, S. K. (1996) Effect of aging on the physico-chemical and morphological properties in the Hanwoo beef by the grade. Korean J. Anim. Sci. Technol. 38, 589-596.

22. Hausman, G. J., Dodson, M. V., Ajuwon, K., Azain, M., Barnes, K. M., Guan, L. L., Jiang, Z., Poulos, S. P., Sainz, R. D., Smith, S., Spurlock, M., Novakofski, J., Fernyhough and Bergen, W. G. (2009) Board-invited review: the biology and regulation of pre-adipocytes and adipocytes in meat animals. J. Anim. Sci. 87, 1218-1246.

23. Huffman, K. L., Miller, M. F., Hoover, L. C., Wu, C. K., Brittin, H. C., and Ramsey, C. B. (1996) Effect of beef tenderness on consumer satisfaction with steaks consumed in the home and restaurant. J. Anim. Sci. 74, 91-97.

24. Insausti, K., Beriain, M. J., Alzueta, M. J., Carr, T. R., and Purroy, A. (2004) Lipid composition of the intramuscular fat of beef from Spanish cattle breeds stored under modified 
atmosphere. Meat Sci. 66, 639-646.

25. Irurueta, M., Cadoppi, A., Langman, L., Grigioni, G., and Carduza, F. (2008) Effect of aging on the characteristics of meat from water buffalo grown in the Delta del Paranà region of Argentina. Meat Sci. 79, 529-533.

26. Jeremiah, L. E., Dugan, M. E. R., Aalhus, J. L., and Gibson, L. L. (2003) Assessment of the relationship between chemical components and palatability of major beef muscles and muscles groups. Meat Sci. 65, 1013-1019.

27. Joseph, R. L. and Connolly, J. (1977) The effects of suspension method, shilling rate and post-mortem aging period on beef quality. J. Food Technol. 12, 231-247.

28. Kim, K. H., Kim, Y. S., Lee, Y. K., and Baik, M. G. (2000) Postmortem muscle glycolysis and meat quality characteristics of intact male Korean native (Hanwoo) cattle. Meat Sci. 55, 47-52.

29. Kim, C. J. and Lee, E. S. (2003) Effects of quality grade on the chemical, physical and sensory characteristics of Hanwoo (Korean native cattle) beef. Meat Sci. 63, 397-405.

30. Koohmaraie, M. (1996) Biochemical factors regulating the toughening and tenderization processes of meat. Meat Sci. 43, 193-201.

31. Laster, M. A., Smith, R. D., Nicholson, K. L., Nicholson, J. D. W., Miller, R. K., and Griffin, D. B. (2008) Dry versus wet aging of beef: Retail cutting yields and consumer sensory attribute evaluations of steaks from ribeyes, strip loins, and top sirloins from two quality grade groups. Meat $S c i$. 80, 795-804.

32. Lawrie, R. A. and Ledward, D. A. (2006) Lawrie's Meat Science $7^{\text {th }}$ ed. Cambridge: Woodhead Publishing Limited.

33. Lee, M. S., Apple, J. K., Yancey, J. W. S., Sawyer, J. T., and Johnson, Z. B. (2008) Influence of vacuum-aging period on bloom development of the beef gluteus medius from top sirloin butts. Meat Sci. 80, 592-598.

34. Lynch, A. Buekley, D. J., Calvin, K., Mullen, A. M., Troy, D. J., and Kerry, J. (2002) Evaluation of hit Steak color from Fresian, Hereford, and Charolais heifers pastured or over wintered prior to slaughter. Meat Sci. 61, 227-232.

35. Mandell, I. B., Buchanan-Smith, J. G., and Campbell, C. P. (1998) Effects of forage vs. grain feeding on carcass characteristics, fatty acid composition, and beef quality in Limousine-cross steers when time on feed is controlled. J. Anim. Sci. 76, 2619- 2630.

36. Mann, N. J., Ponnampalam, E. N., Yep, Y., and Sinclair, A. J. (2003) Feeding regimes affect fatty acid composition in Australian beef cattle. Asia Pacific J. Clin. Nutr. 12, S38.

37. Marmer, W. N., Maxwell, R. J., and Williams, J. E. (1984) Effects of dietary regimen and tissue site on bovine fatty acid profiles. J. Anim. Sci. 59, 109-121.

38. May, S. G., Dolezal, H. G., Gill, D. R. Ray, F. K., and Buchanan, D. S. (1992) Effects of days fed, carcass grade traits, and subcutaneous fat removal on postmortem muscle characteristics and beef palatability. J. Anim. Sci. 70, 444-453.

39. McBee, J. L. and Wiles, J. A. (1967) Influence of marbling and carcass grade on the physical and chemical characteristics of beef. J. Anim. Sci. 26, 701-704.
40. McKenna, D. R., Mies, P. D., Baird, B. E., Pfeiffer, K. D., Ellebracht, J. W., and Savell, J. W. (2005) Biochemical and physical factors affecting discoloration characteristics of 19 bovine muscles. Meat Sci. 70, 665-682.

41. Miller, R. K., Cross, H. R., Crouse, J. D., and Tatum, J. D. (1987) The influence of diet and time on feed on carcass traits and quality. Meat Sci. 19, 303-313.

42. Miller, R. K., Rockwell, L. C., Lunt, D. K., and Carstens, G. E. (1996) Determination of the flavor attributes of cooked beef from cross-bred Angus steers fed corn-or barley-based diets. Meat Sci. 44, 235-243.

43. Miller, M. F., Carr, M. A., Ramsey, C. B., Crockett, K. L., and Hoover, L. C. (2001) Consumer thresholds for establishing the value of beef tenderness. J. Anim. Sci. 79, 3062-3068.

44. Monsón, F., Sañudo, C., and Sierra, I. (2005) Influence of breed and ageing time on the sensory meat quality and consumer acceptability in intensively reared beef. Meat Sci. 71, 471-479.

45. Moon, S. S., Hwang, I. H., Jin, S. K., Lee J. G., Joo, S. T., and Park, G. B. (2003) Carcass traits determining quality and yield grades of Hanwoo steer. Asian-Aust. J. Anim. Sci. 16, 1049-1054.

46. Moon, S. S., Yang, H. S., Park, G. B., and Joo, S. T. (2006) The relationship of physiological maturity and marbling judged according to Korean grading system to meat quality traits of Hanwoo beef females. Meat Sci. 74, 516-521.

47. Nishimura, T., Hattori, A., and Takahashi, K. (1999) Structural changes in intramuscular connective tissue during the fattening of Japanese Black cattle: Effect of marbling on beef tenderization. J. Anim. Sci. 77, 93-104.

48. NLCF. 2004. Korean Carcass Grading Standard. National Livestock Cooperatives Federation, Korea.

49. Novakofski, J., and Brewer, M. S. (2006) The paradox of toughening during the aging of tender steaks. J. Food Sci. 71, S473-S479.

50. Oka, A., Iwaki, F., Dohgo, T., Ohtagaki, S., Noda, M., Shiozaki, T., Endoh O., and Ozaki, M. (2002) Genetic effects on fatty acid composition of carcass fat of Japanese Black Wagyu steers. J. Anim. Sci. 80, 1005-1011.

51. Okumura, T., Saito, K., Sakuma, H., Nade, T., Nakayama S., Fujita, K., and Kawamura. T (2007). Intramuscular fat deposition in principal muscles from twent-four to thirty months of age using identical twins of Japanese Black steers. $J$. Anim. Sci. 85, 1902-2907.

52. Osman, R. O., Abd El Gelil, F. M., El-Noamany, H.M., and Dawood, M. G. (2000) Oil content and fatty acid composition of some varieties of barley and sorghum grains. Grasas y Aceites 51, 157-162.

53. Park, G. B., Moon, S. S., Ko, Y. D., Ha, J. K., Lee, J. G., Chang, H. H., and Joo, S.T. (2002) Influence of slaughter weight and sex on yield and quality grades of Hanwoo (Korean native cattle) carcasses. J. Anim. Sci. 80, 129-136.

54. Ponnampalam, E. N., Mann, N. J., and Sinclair, A. J. (2006) Effect of feeding system on omega-3 fatty acids, conjugated linoleic acid and trans fatty acids in Australian beef cuts: potential impact on human health. Asia Pcific J. Clin. Nutr. 
15, 21-29.

55. Rule, D. C., MacNeil, M. D., and Short, R. E. (1997) Influence of sire growth potential, time on feeding, and growingfinishing strategy on cholesterol and fatty acids of the ground carcass and longissimus muscle of beef steers. J. Anim. Sci. 75, $1525-1533$.

56. Rule, D. C. (1997) Direct transesterification pf total fatty acids of adipose tissue, and of freeze-dried muscle and liver with boron-trifluoride in methanol. Meat Sci. 46, 23-32.

57. Rumsey, T. S., Oltjen, R. R., Bovard, K. P., and Priode, B. M. (1972) Influence of widely diverse finishing regimens and breeding on depot fat composition in beef cattle. J. Anim. Sci. 35, 1069-1075.

58. Sami, A. S., Augustini, C., and Schwarz, F. J. (2004) Effect of feeding intensity and time on feed on intramuscular fatty acid composition of Simmental bulls. J. Anim. Physiol. Anim. Nutr. 88, 179-187.

59. Scollan, N., Hocquette, J. F., Nuernberg, K., Dannenberger, D., Richardson R. I, and Moloney, A. (2006) Innovations in beef production systems that enhance the nutritional and health value of beef lipids and their relationship with meat quality. Meat Sci. 74, 17-33.

60. Sidhu, R. S., Hammond, B. G., Fuchs, R. L., Mutz, J. N., Holden, L. R., George, B., and Olson, T. (2000) Glyphosate-tolerant corn: The composition and feeding value of grain from glyphosate-tolerant corn is equivalent to that of conventional corn (Zea mays L.). J. Agr. Food Chem. 48, 2305-2312.

61. Skelly, G. C., Standfor, W. C., and Edwards, R. L., (1973) Bovine fat composition and its relation to animal diet and carcass characteristics. J. Anim. Sci. 36, 576-580.

62. Smith, S. B. and Crouse, J. D. (1984) Relative contributions of acetate, lactate and glucose to lipogenesis in bovine intramuscular and subcutaneous adipose tissue. J. Nutr. 114, 792800.

63. Spanier, A. M., Flores, M., McMillin K. W., and Bidner, T. D. (1997) The effect of post-mortem aging on meat flavor quality in Brangus beef. Correlation of treatments, sensory, instrumental and chemical descriptors. Food Chem. 59, 531538.

64. Stelzleni, A. M. and Johnson, D. D. (2008) Effect of days on concentrate feed on sensory off-flavor descriptor and fatty acid profiles for selected muscles from cull beef cows. Meat Sci. 79, 382-393.
65. Tatum, J. D., Smith, G. C., Berry, G. C., Murphey, B. W., Williams, C. E., and Carpenter, Z. L. (1980) Carcass characteristics, time on feed and cooked beef palatability attributes. $J$. Anim. Sci. 50, 833-840.

66. Van Koevering, M. T., Gill D. R., Owens, F. N., Dolezal, H. G., and Strasia, C. A. (1995) Effect of time on feed on performance of feedlot steers, carcass characteristics, and tenderness and composition of longissimus muscles. J. Anim. Sci. 73, 21-28.

67. Webb, E. C. and O'Neill, H. A. (2008) The animal fat paradox and meat quality. Meat Sci. 80, 28-36.

68. Williams, S. E., Tatum, J. D., and Stanton, T. L. (1989) The effects of muscle thickness and time on feed on hot fat trim yields, carcass characteristics and boneless subprimal yields. J. Anim. Sci. 67, 2669-2676.

69. Wismer, W. V., Okine, E. K., Stein, A., Seibel, M. R., and Goonewardene, L. A. (2008) Physical and sensory characterization and consumer preference of corn and barley-fed beef. Meat Sci. 80, 857-863.

70. Wood, J. D., Enser, M., Fisher, A. V., Nute, G. R., Sheard, P. R., Richardson, R. I., Hughes, S. I., and Whittington F. M. (2008) Fat deposition, fatty acid composition and meat quality: A review. Meat Sci. 78, 343-358.

71. Wood, J. D., Richardson, R. I., Nute, G. R., Fisher, A. V., Campo, M. M., Kasapidou, E., Sheard, P. R., and Enser, M. (2003) Effects of fatty acids on meat quality: a review. Meat Sci. 66, 21-32.

72. Xie, Y. R., Busboom, J. R., Cornforth, D. P., Shenton, H. T., Gaskins, C. T., Johnson, K. A., Reeves J. J., Wright, R. W., and Cronrath, J. D. (1996) Effects of time on feed and postmortem aging on palatability and lipid composition of crossbred Wagyu beef. Meat Sci. 43, 157-166.

73. Xu, C. X., Oh, Y. K., Lee, H. G., Kim, T. G., Li, Z. H., Yin, J. L., Jin, Y. C., Jin, H., Kim Y. J., Kim, K. H., Yeo, J. M., and Choi, Y. J. (2008) Effect of feeding high-temperature, microtime-treated diets with different lipid sources on conjugated linoleic acid formation in finishing Hanwoo steers. J. Anim. Sci. 86, 3033-3044.

74. Zinn, D. A., Durham, R. M., and Hedrick, H. B. (1970) Feedlot and carcass grade characteristics of steers and heifers as influenced by days on feed. J. Anim. Sci. 31, 302-306.

(Received 2012.1.27/Revised 1st 2012.3.22, 2nd 2012.5.30/ Accepted 2012.6.12) 